Case Report

\title{
Update Review and Clinical Presentation in Congenital Insensitivity to Pain and Anhidrosis
}

\author{
L. M. Pérez-López, ${ }^{1}$ M. Cabrera-González, ${ }^{1}$ D. Gutiérrez-de la Iglesia, ${ }^{1}$ \\ S. Ricart, ${ }^{2}$ and G. Knörr-Giménez ${ }^{1}$ \\ ${ }^{1}$ Pediatric Orthopaedic Surgery Department, Sant Joan de Déu Children's Hospital, University of Barcelona, Barcelona, Spain \\ ${ }^{2}$ Pediatric Rheumatology Department, Sant Joan de Déu Children's Hospital, University of Barcelona, Barcelona, Spain \\ Correspondence should be addressed to L. M. Pérez-López; lperezl@hsjdbcn.org
}

Received 28 June 2015; Revised 14 September 2015; Accepted 16 September 2015

Academic Editor: Piero Pavone

Copyright (C) 2015 L. M. Pérez-López et al. This is an open access article distributed under the Creative Commons Attribution License, which permits unrestricted use, distribution, and reproduction in any medium, provided the original work is properly cited.

\begin{abstract}
Introduction. Congenital insensitivity to pain and anhidrosis (CIPA) or hereditary sensory and autonomic neuropathy type IV is an extremely rare syndrome. Three clinical findings define the syndrome: insensitivity to pain, impossibility to sweat, and mental retardation. This pathology is caused by a genetic mutation in the NTRK1 gene, which encodes a tyrosine receptor (TrkA) for nerve growth factor (NGF). Methods. The consultation of a child female in our center with CIPA and a tibia fracture in pseudoarthrosis encouraged us to carefully review literature and examine the therapeutic possibilities. A thorough review of literature published in Pubmed was done about CIPA and other connected medical issues mentioned in the paper. Conclusions. The therapeutic approach of CIPA remains unclear. The preventive approach remains the only possible treatment of CIPA. We propose two new important concepts in the therapeutic approach for these patients: (1) early surgical treatment for long bone fractures to prevent pseudoarthrosis and to allow early weight bearing, decreasing the risk of further osteopenia, and (2) bisphosphonates to avoid the progression of osteopenia and to reduce the number of consecutive fractures.
\end{abstract}

\section{Introduction}

Congenital insensitivity to pain and anhidrosis (CIPA), also known as hereditary sensory and autonomic neuropathy type IV, is an extremely rare syndrome. The first reference to a similar pathology was mentioned by Dearborn in the early 1900s [1], and it was published in 1963 by Swanson [2]. Three clinical findings define the syndrome: insensitivity to pain, inability to sweat, and mental retardation [3,4]. Only a few hundreds of cases of CIPA have been recently published worldwide $[5,6]$. This condition occurs with an incidence of 1 in 125 million newborns [7].

The pathogenesis of CIPA is characterized by a genetic loss-of-function mutation of the NTKR1 gene (locus 1q 2122) $[8,9]$. Multiple new mutations have been progressively described [10-16]. NTRK1 mutations imply an alteration in TrkA, a NGF receptor. NGF is involved in surveillance of nociceptive sensory neurons and sympathetic autonomic neurons and collaborates in the activation and homeostasis of other cellular types so that a NTRK1 mutation will cause deficient development of [17-20]

(1) the afferent somatic sensory system for pain and temperature, located in the dorsal root ganglion sensory neurons,

(2) the autonomic sympathetic neuronal system, which implies loss of the innervation of eccrine sweat glands by sympathetic neurons,

(3) the central nervous system,

(4) the bidirectional communication between the immune system and the nervous system (NGF has a relevant role in the signal pathway of $B$ lymphocytes through three processes: Trk A phosphorylation, cytoskeleton assemblage, and MAP kinase activation).

The molecular alteration in the function of NGF in turn also alters the normal process of fracture consolidation [21]. 
Normal osteoblast/osteoprogenitor differentiation and proliferation are hindered, tending to result in fibroblast differentiation of multipotent stromal mesenchymal cells and periosteal cells.

Bone metabolism is also affected by the lack of nociceptive fibers, present not only in the skin but also in the skeletal system [22]. Due to the trophic role that nociceptive fibers may play in the skeletal system, bone fractures are very common [23].

\section{Case Presentation}

Medical record and radiographic data of the present case were reviewed and reported in a study approved by the department of documentation of our hospital. The patient's parents also gave their consent. A thorough review of the PubMed literature on CIPA and associated medical conditions mentioned in this paper was performed (Table 1). This case report is an illustrative example of a patient affected by CIPA.

We present a case involving a seven-year-old, female child of Spanish nationality. She had been evaluated in another center for episodes of recurrent fever. After a long diagnostic process including a pertinent genetic study which detected two mutations in the NTRK1 gene responsible for CIPA, she was diagnosed with the syndrome [8]. Her parents were healthy, and no consanguinity was present.

Clinical exploration revealed absence of a pain response, recurrent episodes of fever, sweating deregulation, mental retardation, cutaneous autolesions, fracture without consolidation, avascular necrosis (Figure 1), demineralized bones, generalized osseous destruction (Figure 2), warm and dry skin with thickening of the soles and palms, and lower limb edema (Figures 3(a), 3(b), and 3(c)) [5, 24-26].

The patient was referred to our center four months after fracture of the middle shaft of the right tibia. Radiologic signs of hypertrophic pseudoarthrosis were present (Figure 4). An elastic intramedullary nailing was carried out [27]. Complete radiological consolidation of the fracture was achieved five months after the surgery (Figure 5).

In the following months, several fractures occurred, including a fifth metatarsal fracture in the right foot (Figure 1) and a fourth metatarsal fracture in the left foot, a right femoral middle shaft fracture that was surgically treated with good results (Figures 6(a), 6(b), and 6(c)), and an epiphysiolysis at the distal shaft of the right tibia. In CIPA, due to the alteration of the bone fracture metabolism, hypertrophic bone callus (Figures 1, 4, and 6(c)) and pseudoarthrosis (Figure 4) are very common. In the present patient, bone consolidation was only achieved when a surgical technique was applied.

During this period of time with recurrent fractures, treatment with bisphosphonates was started. A dose of $1 \mathrm{mg} / \mathrm{Kg} /$ day during 3 consecutive days of intravenous pamidronate was administered every four months, for one year. We obtained good results in preventing new fractures at upper and lower limbs, skull, and spine bones at 5 years of follow-up. No adverse effects were seen regarding pamidronate infusion or during the follow-up.

At 5 years of follow-up, patient has progressed.

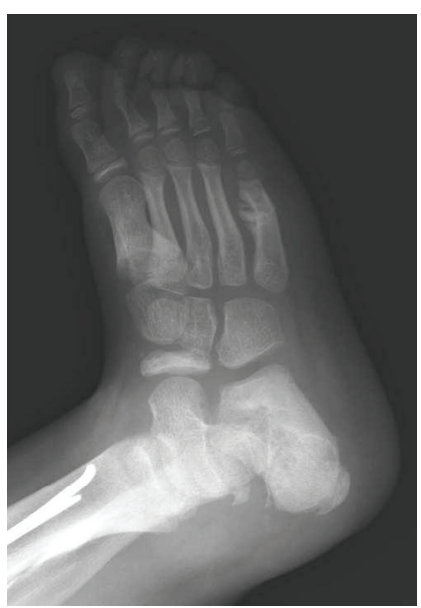

FIGURE 1: Navicular avascular necrosis and fifth metatarsal fracture in the right foot with hypertrophic bone callus.

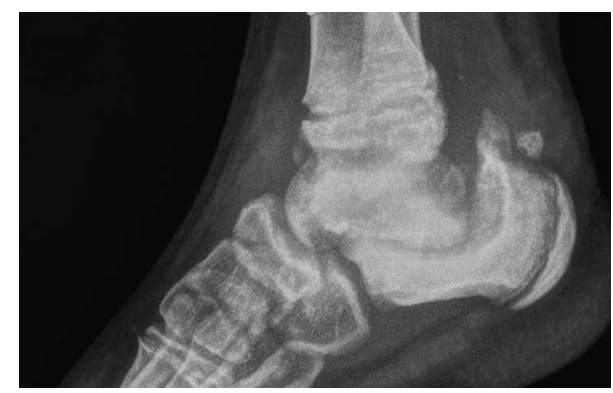

FIGURE 2: Demineralized bones and generalized osseous destruction.

\section{Discussion}

CIPA is an autosomal recessive disorder [8]. Some cases of consanguinity have been described among affected patients $[7,28]$. Apart from the already well-defined genetic transmission of CIPA, there is an infrequent non-Mendelian inheritance characterized by uniparental disomy of chromosome 1 [10]. It is described by the transmission of an autosomal recessive pathology from only one affected parent. The molecular genetic analysis of the presented patient detected two heterozygous mutations in the NTRK1 gene (c.2205+1G>T in intron 16 and c.360-45C>A in intron 3), found also in her mother, suggesting then uniparental disomy.

The therapeutic approach to CIPA is still evolving and remains controversial [7]. There is no definitive agreement regarding its management, and therapeutic options are restricted to treatment of symptoms and protection from selfmutilation, fractures, and wound infections, which may lead to amputation. Such limited treatment options imply potentially catastrophic consequences of the natural pathologic evolution of the disease. Fractures associated with CIPA may be devastating and deeply affect the patient's functionality. Surgical treatment provides stability to the focal point of the fracture, helping to provide definitive consolidation. Moreover, immobilization contributes to accelerated bone 
TABLE 1: Thorough review of the PubMed literature on CIPA and associated medical conditions mentioned in this paper was performed.

\begin{tabular}{|c|c|c|}
\hline References & Year of publication & Particularity of the observation and remarks for each reading \\
\hline Dearborn [1] & 1932 & First reference, in literature, to a similar disease \\
\hline Swanson [2] & 1963 & First reference, in literature, to CIPA \\
\hline Nishida [3] & 1951 & \multirow{2}{*}{$\begin{array}{l}\text { Three clinical representative findings: insensitivity to pain, } \\
\text { inability to sweat, and mental retardation }\end{array}$} \\
\hline Tunçbilek et al. [4] & 2005 & \\
\hline $\begin{array}{l}\text { Rosemberg et al. [5] } \\
\text { review }\end{array}$ & 1994 & Only 32 cases have been published worldwide \\
\hline Gao et al. [6] & 2013 & $\begin{array}{l}\text { Only some hundreds of cases have been published } \\
\text { worldwide }\end{array}$ \\
\hline $\begin{array}{l}\text { Daneshjou et al. } \\
\text { [7] }\end{array}$ & 2012 & Incidence 1 in 125 million newborns \\
\hline Indo et al. [8] & 1996 & \multirow{2}{*}{$\begin{array}{l}\text { CIPA pathogenesis: genetic loss-of-function mutation } \\
\text { the NTKR1 gene (locus 1q 21-22). NTKR1 mutations } \\
\text { imply an alteration in TrKA, A NGF receptor }\end{array}$} \\
\hline Indo et al. [9] & 1997 & \\
\hline Indo et al. [8] & 1996 & Autosomal recessive disorder \\
\hline Indo $[10]$ & 2001 & $\begin{array}{l}\text { Not only autosomal recessive inheritance, but also } \\
\text { uniparental disomy (non-Mendelian inheritance of } \\
\text { autosomal recessive disease from a single carrier parent, as } \\
\text { the exposed case) }\end{array}$ \\
\hline Indo [10] review & 2001 & \multirow{8}{*}{$\begin{array}{l}\text { Novel mutation and polymorphism in the NTRK1 gene } \\
\text { causing CIPA }\end{array}$} \\
\hline Indo et al. [15] & 2001 & \\
\hline Bonkowsky et al. [11] & 2003 & \\
\hline Lin et al. [12] & 2010 & \\
\hline Mardy et al. [16] & 2001 & \\
\hline Miura et al. [13] & 2000 & \\
\hline Weier et al. [14] & 1995 & \\
\hline Bonkowsky et al. [11] & 2003 & \\
\hline Indo [25] review & 2002 & $\begin{array}{l}\text { A very profuse resume of clinical and genetic characteristics } \\
\text { of CIPA }\end{array}$ \\
\hline Indo [18] & 2010 & \multirow{6}{*}{$\begin{array}{l}\text { NGF receptor failure causes a deficient development of dorsal } \\
\text { root neurons (pain and temperature sensory system) } \\
\text { autonomic sympathetic neural system (eccrine sweat glands } \\
\text { innervation) } \\
\text { Central nervous system } \\
\text { The signal pathway of B lymphocytes }\end{array}$} \\
\hline Indo [19] & 2012 & \\
\hline Tanaka et al. [20] & 1990 & \\
\hline $\begin{array}{l}\text { Schwarzkopf et al. [17] } \\
\text { review }\end{array}$ & 2005 & \\
\hline Indo $[25]$ & 2002 & \\
\hline Melamed et al. [21] & 2004 & \\
\hline Grills and Schuijers [24] & 1998 & $\begin{array}{l}\text { NGF function disruption also causes an altered process of } \\
\text { fracture consolidation }\end{array}$ \\
\hline Fruchtman et al.[26] & 2013 & \multirow{2}{*}{$\begin{array}{l}\text { Descriptive clinical presentation including morbidity } \\
\text { conditions (some of these clinical facts are also present in the } \\
\text { case reported) }\end{array}$} \\
\hline Yang et al. [27] & 2013 & \\
\hline Jarade et al. [35] review & 2002 & Ocular manifestations \\
\hline Brandes and Stuth [39] & 2006 & \multirow{2}{*}{ Anaesthetic considerations } \\
\hline Oliveira et al. [40] & 2009 & \\
\hline Abdulla et al. [33] & 2014 & $\begin{array}{l}\text { Heterotopic ossification and callus formation following } \\
\text { fractures, eventually Charcot's joint }\end{array}$ \\
\hline Schreiber et al. [41] & 2005 & Insulin-related difficulties \\
\hline
\end{tabular}




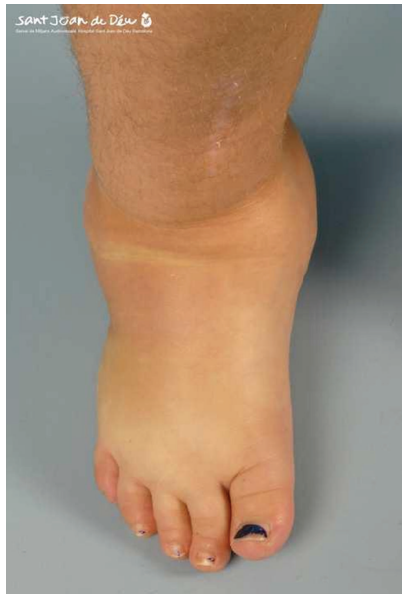

(a)

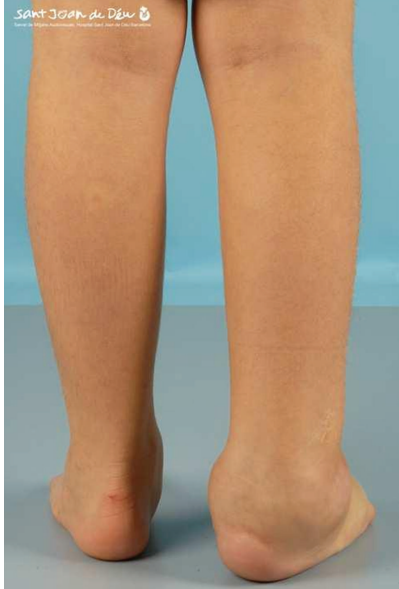

(b)

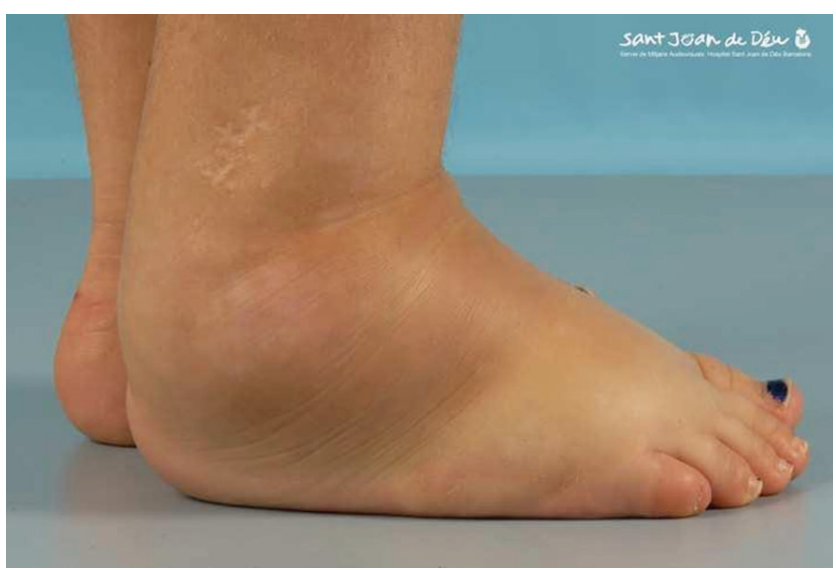

(c)

Figure 3: Lower limb edema.

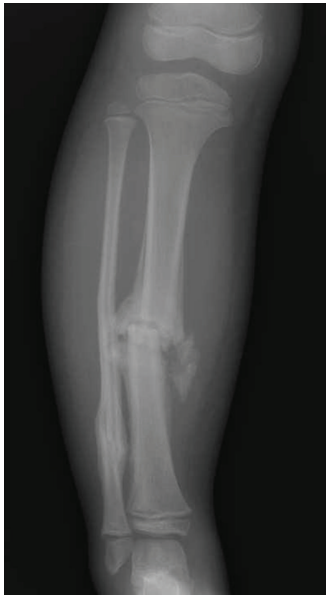

FIGURE 4: Hypertrophic bone callus.

demineralization. Surgical fracture repair allows for early weight bearing, diminishing the risk of further osteopenia, which is also usually present in these patients as a part of their associated neurogenic arthropathy (Figure 3) [21].

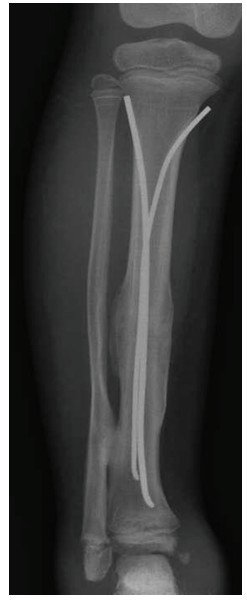

FIGURE 5: Complete radiological consolidation of the tibia fracture was achieved five months after the surgery.

For all of these reasons, we recommend early surgical treatment of fractures. It allows for more rapid functional recovery, reducing the risk of accelerated osteopenia due to immobilization. 


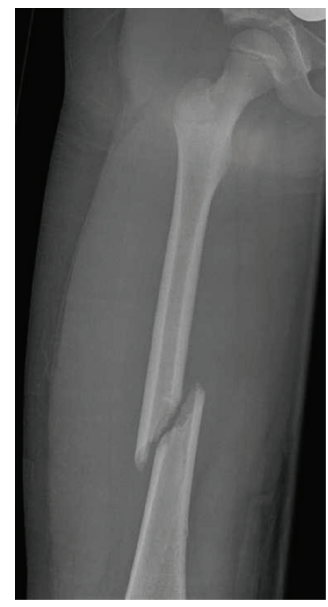

(a)

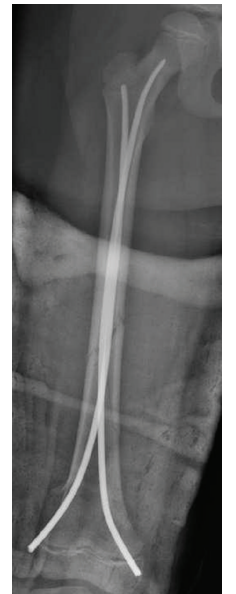

(b)

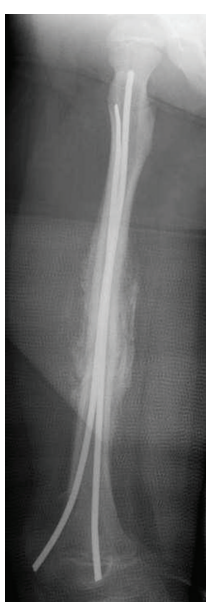

(c)

FIGURE 6: Right femoral middle shaft fracture that was surgically treated with good results. Hypertrophic bone callus associated.

The use of bisphosphonates in patients affected by CIPA had never been mentioned before in literature. Due to our previous good experience with pamidronate in treating osteoporotic fractures for disuse in children with different medical conditions $[29,30]$, we made a therapeutic approach with pamidronate as a compassionate use in this child. We obtained good results in preventing new fractures.

These two therapeutic observations might be relevant in the absence of specific treatment for CIPA. However, we may not forget that further studies addressing CIPA management are needed to provide more rigorous and scientific conclusions.

CIPA may present various signs and symptoms that can be misleading. The differential diagnoses of this pathology include radicular hereditary sensory neuropathy (HSN I); hereditary sensory and autonomic neuropathy (HSN II); familial dysautonomia or Riley-Day syndrome (HSN III) [31]; congenital indifference to pain (HSN V) [32]; and Lesch-Nyhan syndrome. Corneal ulcers are also relatively frequent in patients with CIPA. A differential diagnosis of neurotrophic keratitis may be taken into consideration [33, 34]. Among all these diagnostic possibilities and according to Raspall-Chaure [29],

CIPA must be the first diagnostic hypothesis when assessing a patient with insensitivity to pain, anhidrosis, and selfmutilation.

According to literature, the first step in the diagnosis of CIPA syndrome is consideration of the clinical presentation based on the combination of three basic signs: insensitivity to pain, anhidrosis, and mental retardation [3, 4]. Other possible signs may be associated: impaired temperature sensation [5], facial alterations [6], mandibular osteolysis [7], dental caries [6], and premature tooth loss [6]; repetitive soft tissue and osseous infections of hematogenous origin [33], mainly caused by S. aureus [25]; self-mutilating behavior [7]; occasional microcephaly $[5,24]$; urine and fecal incontinence [11]; growth disturbances; and heterotopic ossification [7, 35, 36].
Neurological laboratory tests may provide additional information. Short-latency somatosensory evoked potentials show marked prolongation of the central conduction time [19] and microneurography reveals abnormal activity of somatic A-delta and C fibers in the nerves of the skin $[6,37$, 38]. A negative sympathetic skin response may also be helpful in the diagnosis due to the lack of sudomotor nerves in skin biopsy [38].

Pharmacologic tests that evaluate autonomic function are also useful. The Mecholyl test produces prompt pupillary miosis [24], pain test results abnormal $[6,13,24]$, there is an absence of a flare reaction to the histamine test [24] (although we may find some normal responses to subdermal histamine injection) [11], and the sweat test using pilocarpine reveals a disruption of sweat gland function. Histopathologic evaluation shows a hyperplastic epidermis with acanthosis and hyperkeratosis and a decreased amount of sweat and sebaceous glands [6].

Finally, molecular evaluation that reveals mutations of the NTKR1 gene provides a definitive diagnosis $[19,24]$.

About the anesthetic considerations [39, 40], although pain stimuli are absent, anxiety associated with surgical procedures may generate stress and consequent hemodynamic instability. It is necessary to minimize preoperative apprehension and anxiety with the use of sedatives. Also the autonomic response to surgery is inconsistent and erratic, which results in difficulty determining the necessary anesthetic doses in advance. Finally, temperature control is crucial. Malignant hyperthermia or hypothermia may be lethal.

NGF-TrkA pathway has a role in the morphogenesis of the endocrine pancreas, in insulin secretion in vitro, and in insulin secretion in response to glucose. Patients with CIPA present with alterations of the first phase of insulin secretion [41].

The similarities between CIPA and reflex sympathetic dystrophy are very interesting. Both are characterized by neurogenic inflammation, skin alterations with vasomotor disruption, and osteopenia. 
Some authors have focused on establishing a specific treatment for complex regional pain syndrome by studying the role of receptor tyrosine kinase for NGF in patients with CIPA [29].

The high incidence of infections in patients with CIPA is also problematic. Skin and deep bone infections are the most common types, and Staphylococcus aureus is the most commonly involved pathogen.

Resistance to antibiotics is a frequently occurring limitation in the treatment of these patients [25].

Temperature deregulation may cause recurrent fever, which may lead to death if not recognized early.

Other complications such as trauma or soft tissue/bone infection may decrease condition of the survival rate, although all are treatable conditions if diagnosed in a timely manner [7].

The best therapeutic approach to patients with CIPA appears to be based on prophylactic measures such as braces for early weight bearing in nonsurgical fractures and accurate follow-up to avoid missing complications. We propose an unusual treatment challenge, with an early surgical treatment for long bone fractures and early use of bisphosphonates as follows.

Therapeutic proposals are as follows:

(1) Surgical fracture repair to achieve an early functional recovery that avoids a final destructive situation.

(2) Bisphosphonates use to manage osteoporosis.

Addressing the cause of CIPA as opposed to solely symptomatic treatment seems to be the optimal therapeutic approach. If CIPA results from loss-of-function mutations in the NTRK1 gene encoding TrkA, then molecular treatment involving a receptor tyrosine kinase for NGF would be the most effective therapeutic technique.

\section{Disclosure}

There were not any financial relationships that could be broadly relevant to the work. Our institution has not received any sort of support state. We have not received any financial support. None of the authors has received or may receive any personal payment or in-kind benefit or other professional benefits from a commercial entity. We have also followed the rules of good scientific practice, according to ethical responsibilities of all authors.

\section{Conflict of Interests}

None of the authors has directly received research funding and/or has potential conflict of interests.

\section{Acknowledgments}

The authors thank the patient and her parents for their kind collaboration. Also, they would like to express their gratitude for Carlos Aláez (Department of Photography, Sant Joan de Déu University Children's Hospital, Barcelona) for his help with preparation of the images.

\section{References}

[1] G. Dearborn, "A case of congenital general pure analgesia," Journal of Nervous \& Mental Disease, vol. 75, no. 6, pp. 612-615, 1932.

[2] A. G. Swanson, "Congenital insensitivity to pain with anhydrosis. A unique syndrome in two male siblings," Archives of Neurology, vol. 8, no. 3, pp. 299-306, 1963.

[3] G. Nishida, "Congenital anhidrosis," Saishin Igaku, vol. 6, pp. 1100-1104, 1951.

[4] G. Tunçbilek, C. Öztekin, and A. Kayikçioğlu, "Calcaneal ulcer in a child with congenital insensitivity to pain syndrome," Scandinavian Journal of Plastic and Reconstructive Surgery and Hand Surgery, vol. 39, no. 3, pp. 180-183, 2005.

[5] S. Rosemberg, S. K. Nagahashi Marie, and S. Kliemann, "Congenital insensitivity to pain with anhidrosis (hereditary sensory and autonomic neuropathy type IV)," Pediatric Neurology, vol. 11, no. 1, pp. 50-56, 1994.

[6] L. Gao, H. Guo, N. Ye et al., "Oral and craniofacial manifestations and two novel missense mutations of the NTRK1 gene identified in the patient with congenital insensitivity to pain with anhidrosis," PLoS ONE, vol. 8, no. 6, Article ID e66863, 2013.

[7] K. Daneshjou, H. Jafarieh, and S.-R. Raaeskarami, "Congenital insensitivity to pain and anhydrosis (CIPA) syndrome; a report of 4 cases," Iranian Journal of Pediatrics, vol. 22, no. 3, pp. 412416, 2012.

[8] Y. Indo, M. Tsuruta, Y. Hayashida et al., "Mutations in the TRKA/NGF receptor gene in patients with congenital insensitivity to pain with anhidrosis," Nature Genetics, vol. 13, no. 4, pp. 485-488, 1996.

[9] Y. Indo, S. Mardy, M. Tsuruta, M. A. Karim, and I. Matsuda, "Structure and organization of the human TRK A gene encoding a high affinity receptor for nerve growth factor," Japanese Journal of Human Genetics, vol. 42, no. 2, pp. 343-351, 1997.

[10] Y. Indo, "Molecular basis of congenital insensitivity to pain with anhidrosis (CIPA): mutations and polymorphisms in TRKA (NTRK1) gene encoding the receptor tyrosine kinase for nerve growth factor," Human Mutation, vol. 18, no. 6, pp. 462-471, 2001.

[11] J. L. Bonkowsky, J. Johnson, J. C. Carey, A. G. Smith, and K. J. Swoboda, "An infant with primary tooth loss and palmar hyperkeratosis: a novel mutation in the NTRK1 gene causing congenital insensitivity to pain with anhidrosis," Pediatrics, vol. 112, part 1, no. 3, pp. e237-e241, 2003.

[12] Y.-P. Lin, Y.-N. Su, W.-C. Weng, and W.-T. Lee, "Novel neurotrophic tyrosine kinase receptor type 1 gene mutation associated with congenital insensitivity to pain with anhidrosis," Journal of Child Neurology, vol. 25, no. 12, pp. 1548-1551, 2010.

[13] Y. Miura, S. Mardy, Y. Awaya et al., "Mutation and polymorphism analysis of the TRKA (NTRK1) gene encoding a high-affinity receptor for nerve growth factor in congenital insensitivity to pain with anhidrosis (CIPA) families," Human Genetics, vol. 106, no. 1, pp. 116-124, 2000.

[14] H.-U. G. Weier, A. P. Rhein, F. Shadravan, C. Collins, and D. Polikoff, "Rapid physical mapping of the human trk protooncogene (NTRK1) to human chromosome 1q21-q22 by P1 clone selection, fluorescence in situ hybridization (FISH), and computer-assisted microscopy," Genomics, vol. 26, no. 2, pp. 390-393, 1995.

[15] Y. Indo, S. Mardy, Y. Miura et al., "Congenital insensitivity to pain with anhidrosis (CIPA): novel mutations of the TRKA 
(NTRK1) gene, a putative uniparental disomy, and a linkage of the mutant TRKA and PKLR genes in a family with CIPA and pyruvate kinase deficiency," Human Mutation, vol. 18, no. 4, pp. 308-318, 2001.

[16] S. Mardy, Y. Miura, F. Endo, I. Matsuda, and Y. Indo, "Congenital insensitivity to pain with anhidrosis (CIPA): effect of TRKA (NTRK1) missense mutations on autophosphorylation of the receptor tyrosine kinase for nerve growth factor," Human Molecular Genetics, vol. 10, no. 3, pp. 179-188, 2001.

[17] R. Schwarzkopf, V. Pinsk, Y. Weisel, D. Atar, and Y. Gorzak, "Clinical and genetic aspects of congenital insensitivity to pain with anhidrosis," Harefuah, vol. 144, no. 6, pp. 433-437, 2005.

[18] Y. Indo, "Nerve growth factor, pain, itch and inflammation: lessons from congenital insensitivity to pain with anhidrosis," Expert Review of Neurotherapeutics, vol.10, no. 11, pp. 1707-1724, 2010.

[19] Y. Indo, "Nerve growth factor and the physiology of pain: lessons from congenital insensitivity to pain with anhidrosis," Clinical Genetics, vol. 82, no. 4, pp. 341-350, 2012.

[20] M. Tanaka, A. Sotomatsu, H. Kanai, and S. Hirai, "Irondependent cytotoxic effects of dopa on cultured neurons of the dorsal root ganglia," Clinical Neurology, vol. 30, no. 4, pp. 379383, 1990.

[21] I. Melamed, J. Levy, R. Parvari, and E. W. Gelfand, "A novel lymphocyte singnaling defect: trk A mutation in the syndrome of congenital insensitivity to pain and anhidrosis (CIPA)," Journal of Clinical Immunology, vol. 24, no. 4, pp. 441-448, 2004.

[22] K. A. Derwin, R. A. Glover, and E. M. Wojtys, "Nociceptive role of substance-P in the knee joint of a patient with congenital insensitivity to pain," Journal of Pediatric Orthopaedics, vol. 14, no. 2, pp. 258-262, 1994.

[23] E. L. Hill and R. Elde, "Distribution of CGRP-, VIP-, D $\beta H-$-, SP-, and NPY-immunoreactive nerves in the periosteum of the rat," Cell and Tissue Research, vol. 264, no. 3, pp. 469-480, 1991.

[24] B. L. Grills and J. A. Schuijers, "Immunohistochemical localization of nerve growth factor in fractured and unfractured rat bone," Acta Orthopaedica Scandinavica, vol. 69, no. 4, pp. 415419, 1998.

[25] Y. Indo, "Genetics of congenital insensitivity to pain with anhidrosis (CIPA) or hereditary sensory and autonomic neuropathy type IV. Clinical, biological and molecular aspects of mutations in TRKA(NTRK1) gene encoding the receptor tyrosine kinase for nerve growth factor," Clinical Autonomic Research, vol. 12, supplement 1, pp. I20-I32, 2002.

[26] Y. Fruchtman, Z. H. Perry, and J. Levy, "Morbidity characteristics of patients with congenital insensitivity to pain with anhidrosis (CIPA)," Journal of Pediatric Endocrinology and Metabolism, vol. 26, no. 3-4, pp. 325-332, 2013.

[27] L. Yang, S. F. Ji, R. J. Yue, J. L. Cheng, and J. J. Niu, "Old fractures in two patients with congenital insensitivity to pain with anhidrosis: radiological findings," Clinical Imaging, vol. 37, no. 4, pp. 788-790, 2013.

[28] J. P. Metaizeau and J. N. Ligier, "Surgical treatment of fractures of the long bones in children. Interference between osteosynthesis and the physiological processes of consolidation. Therapeutic indications," Journal de Chirurgie, vol. 121, no. 8-9, pp. 527-537, 1984.

[29] M. Raspall-Chaure, M. Del Toro-Riera, M. Gratacós et al., "Congenital insensitivity to pain with anhidrosis associated with congenital myasthenic syndrome," Revista de Neurologia, vol. 41, no. 4, pp. 218-222, 2005.
[30] J. F. Sebestyen, T. Srivastava, and U. S. Alon, "Bisphosphonates use in children," Clinical Pediatrics, vol. 51, no. 11, pp. 1011-1024, 2012.

[31] N. J. Shaw, "Management of osteoporosis in children," European Journal of Endocrinology, vol. 159, supplement 1, pp. S33-S39, 2008.

[32] R. A. Boraz, "Familial dysautonomia (Riley-Day Syndrome): report of case," ASDC Journal of Dentistry for Children, vol. 51, no. 1, pp. 64-65, 1984.

[33] M. Abdulla, S. S. Khaled, Y. S. Khaled, and H. Kapoor, "Congenital insensitivity to pain in a child attending a paediatric fracture clinic," Journal of Pediatric Orthopaedics B, vol. 23, no. 5, pp. 406-410, 2014.

[34] M. Karthikeyan, T. Sreenivas, J. Menon, and D. K. Patro, "Congenital insensitivity to pain and anhydrosis: a report of two cases," Journal of Orthopaedic Surgery, vol. 21, no. 1, pp. 125-128, 2013.

[35] E. F. Jarade, H. F. El-Sheikh, and K. F. Tabbara, "Indolent corneal ulcers in a patient with congenital insensitivity to pain with anhidrosis: a case report and literature review," European Journal of Ophthalmology, vol. 12, no. 1, pp. 60-65, 2002.

[36] G. Szöke, A. Rényi-Vámos, and M. A. Bider, "Osteoarticular manifestations of congenital insensitivity to pain with anhydrosis," International Orthopaedics, vol. 20, no. 2, pp. 107-110, 1996.

[37] M. Nolano, C. Crisci, L. Santoro et al., "Absent innervation of skin and sweat glands in congenital insensitivity to pain with anhidrosis," Clinical Neurophysiology, vol. 111, no. 9, pp. 1596$1601,2000$.

[38] Z. Shorer, S. W. Moses, E. Hershkovitz, V. Pinsk, and J. Levy, "Neurophysiologic studies in congenital insensitivity to pain with anhidrosis," Pediatric Neurology, vol. 25, no. 5, pp. 397-400, 2001.

[39] I. F. Brandes and E. A. E. Stuth, "Use of BIS monitor in a child with congenital insensitivity to pain with anhidrosis," Paediatric Anaesthesia, vol. 16, no. 4, pp. 466-470, 2006.

[40] C. R. D. Oliveira, V. C. Paris, R. A. Pereira, and F. S. T. de Lara, "Anesthesia in a patient with congenital insensitivity to pain and anhidrosis," Revista Brasileira de Anestesiologia, vol. 59, no. 5, pp. 602-609, 2009.

[41] R. Schreiber, J. Levy, N. Loewenthal, V. Pinsk, and E. Hershkovitz, "Decreased first phase insulin response in children with congenital insensitivity to pain with anhidrosis," Journal of Pediatric Endocrinology and Metabolism, vol. 18, no. 9, pp. 873877, 2005. 


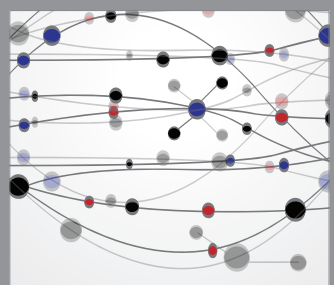

The Scientific World Journal
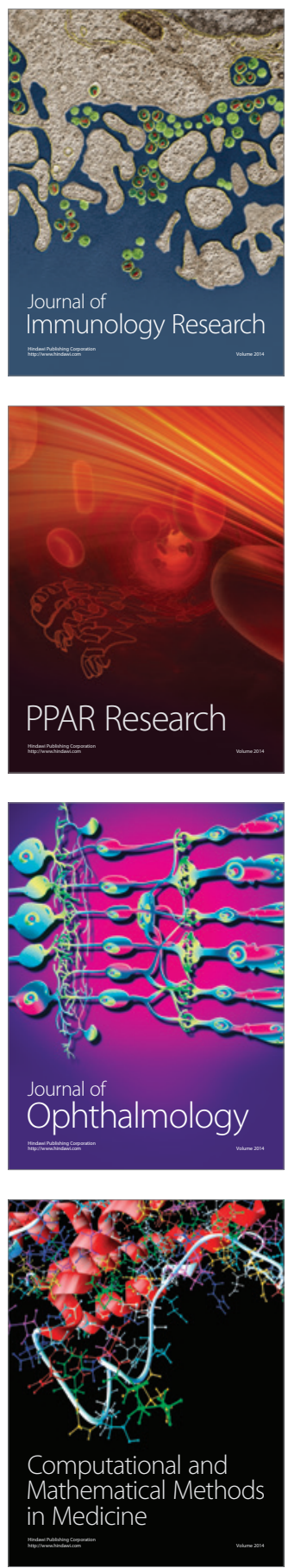

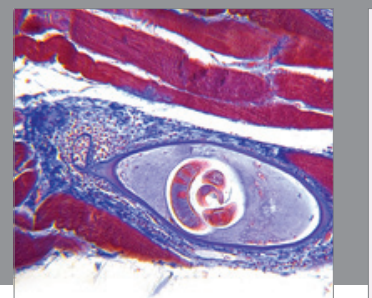

Gastroenterology

Research and Practice
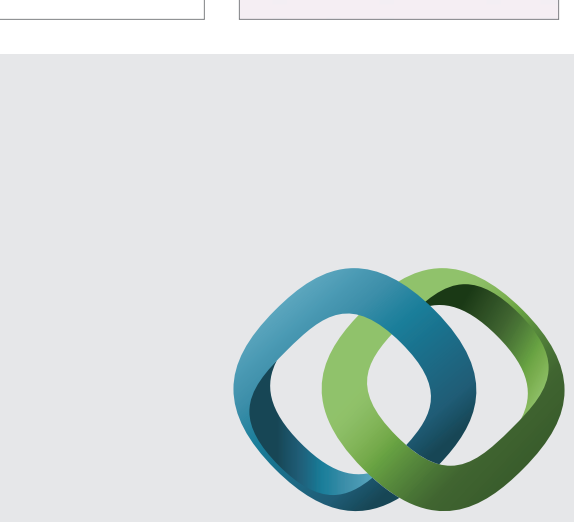

\section{Hindawi}

Submit your manuscripts at

http://www.hindawi.com
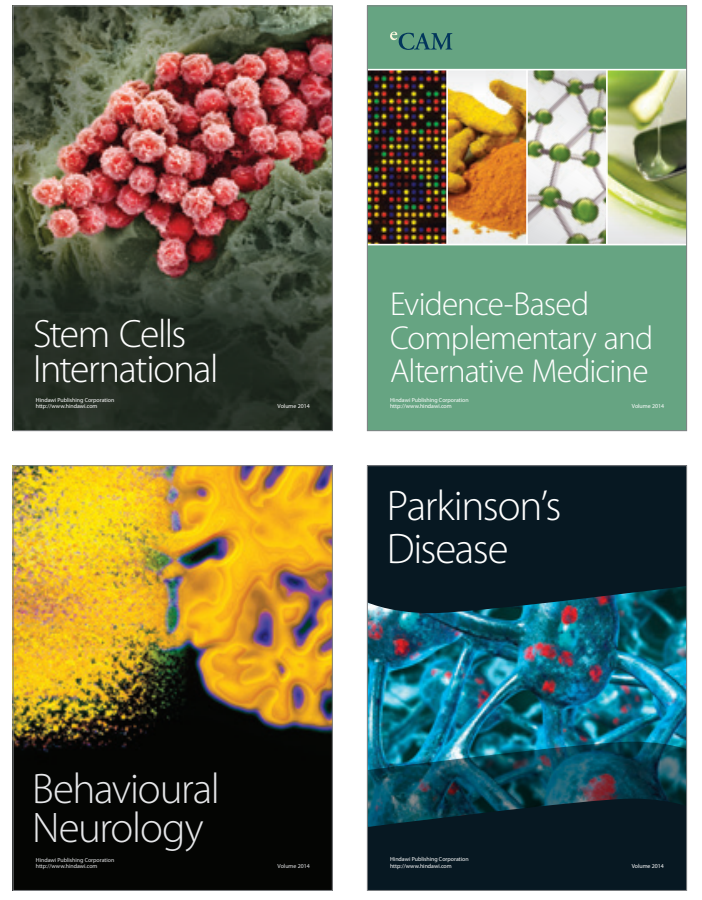
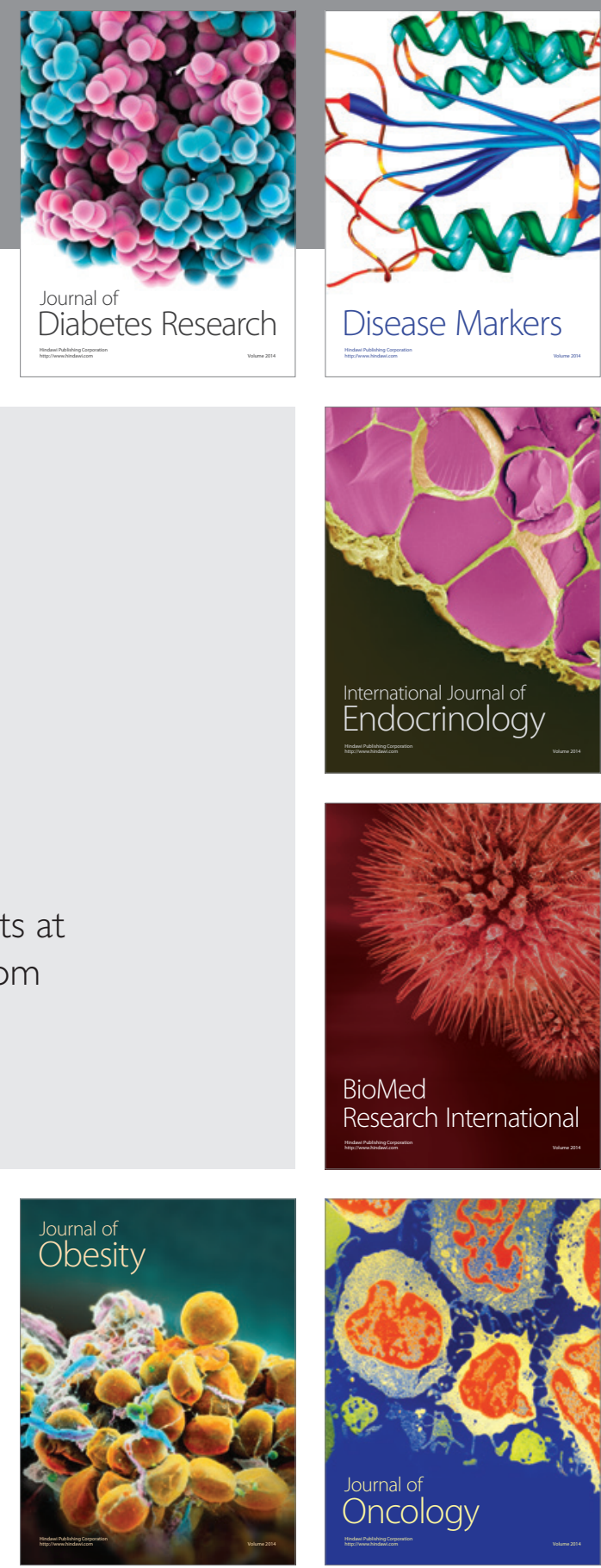

Disease Markers
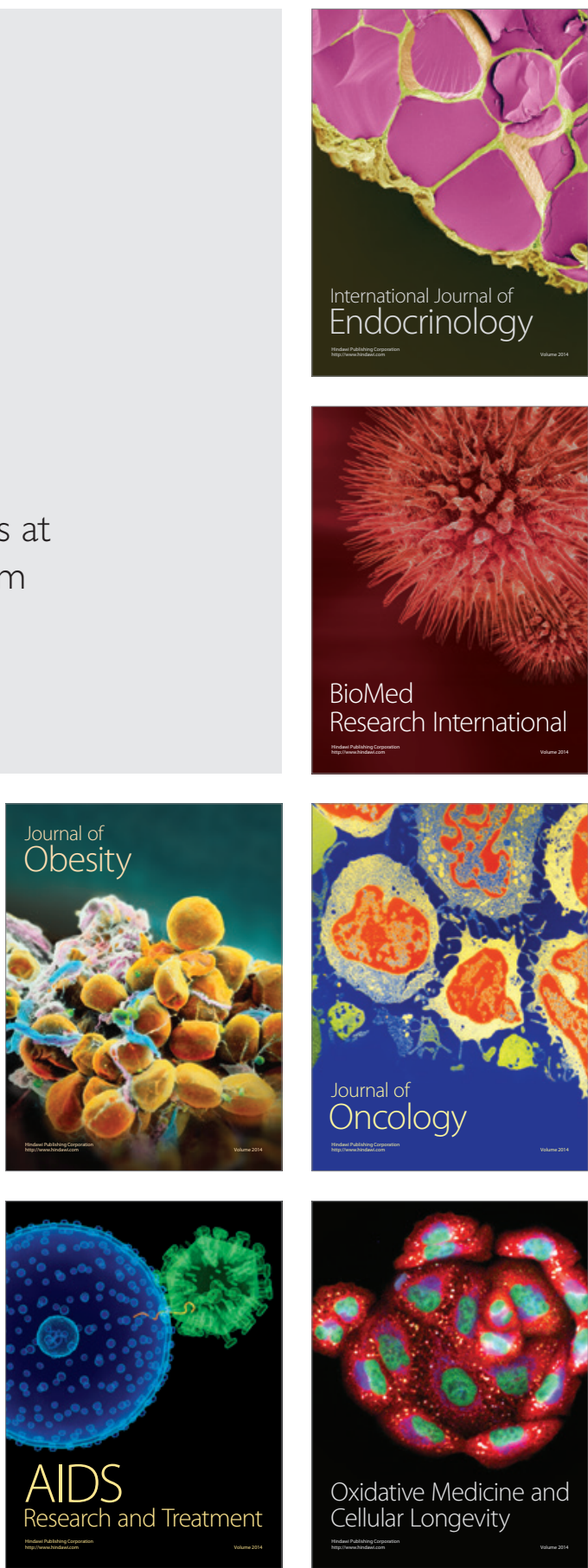